DOI 10. 18307/2017. 0202

(c) 2017 by Journal of Lake Sciences

\title{
中国湖泊沉积物纹层年代学研究进展"
}

\author{
李 凯 ${ }^{1,2}$, 游海涛 $^{3}$, 刘兴起 ${ }^{2,4}$
}

(1: 浙江师范大学化学与生命科学学院环境演变与古生态学实验室,金华 321004)

(2: 中国科学院南京地理与湖泊研究所湖泊与环境国家重点实验室,南京 210008)

(3: 中国科学院大学地球科学学院中国科学院计算地球动力学重点实验室,北京 100049)

( 4 : 首都师范大学资源环境与旅游学院, 北京 100083 )

摘 要: 晚第四纪尤其是全新世是地球气候系统演化的一个关键地质时期, 是探究全球及区域重大气候环境事件, 揭示 其内在演化规律, 预测未来气候变化的关键时段. 国内外发表的文献中, 主要的年代学方法有: $\mathrm{AMS}^{14} \mathrm{C}$ 年代学、石笋 U 系 测年和纹层年代学等.其中纹层年代学被认为是比较精确的定年方法.近年来,国内外学者在中国的一些湖泊中发现了年 纹层沉积,例如龙岗火山区的小龙湾、四海龙湾及二龙湾玛珥湖,柴达木盆地的苏干湖, 青藏高原东部的新路海以及可可 西里地区的库赛湖. 本文概述我国近年来湖泊纹层年代学研究进展, 总结中国湖泊年纹层类型、特征及纹层年代学研究方 法、误差估计等方面的进展, 并提出未来年纹层研究应注意的问题, 以期促进中国湖泊沉积物年纹层研究的进一步发展.

关键词: 年纹层; 纹层年代学; 湖泊沉积物; 中国

\section{Review on lake sediment varve chronology in China}

LI Kai ${ }^{1,2}$, YOU Haitao ${ }^{3} \&$ LIU Xingqi ${ }^{2,4}$

(1: Laboratory of Environmental Change and Paleoecology, College of Chemistry and Life Sciences, Zhejiang Normal University, Jinhua 321004, P.R.China)

(2: State Key Laboratory of Lake Science and Environment, Nanjing Institute of Geography and Limnology, Chinese Academy of Sciences, Nanjing 210008, P.R.China)

(3: Key Lab of Computational Geodynamics of Chinese Academy of Sciences, College of Earth Science, University of Chinese Academy of Sciences, Beijing 100049, P.R.China)

(4: College of Resource Environment and Tourism, Capital Normal University, Beijing 100083, P.R.China)

Abstract: Varve chronology is regarded as a relatively accurate dating method for the late Quaternary, particularly for the Holocene. There are only a few lakes officially reported with annual lamination in China, including Xiaolongwan, Sihailongwan and Erlongwan in Longgang Volcanic Field, Sugan Lake in Chadam Basin, Xinluhai Lake and Kusai Lake on the Tibetan Plateau. Varvebased chronologies have been established in these lakes. Most studies on varved sediments have focused on the reconstructions of paleoenvironment. In this paper, we have introduced the research progresses on varve chronology, summarized the "annual” characteristics of varved lake sediments in China, and emphasized the varve counting, error estimate and verification. We also have pointed out the problems existing in the varve studies that should be paied attentions in the future. This study will standardize the varve chronology researches and promote the development of varve chronologies of lake sediments in China.

Keywords: Varve; chronology; lake sediment; China

年纹层 (varve) 最初的定义是指由两个不同层偶组成的沉积组合, 是瑞典地质学家 De Geer 在 1910 年研 究冰川湖的时候提出的 ${ }^{[1]}$. 目前随着研究的深人, 已经扩展到所有具有 “年”旋回的沉积环境的研究 ${ }^{[2-6]}$. 由 于年纹层的结构和组成受湖泊水文、气候、生物等过程的影响,不同湖泊所发育的年纹层类型不同 ${ }^{[7-8]}$.年纹

* 国家自然科学基金项目 (41472320) 和湖泊与环境国家重点实验室开放基金项目 (2014SKL001) 联合资助. 201602-20 收稿;2016-05-22 收修改稿. 李凯( 1988 ), 男,博士研究生;E-mail: likai@ niglas.ac.cn. 
层厚度、组分及结构变化提供了丰富的古环境变化信息, 连续的纹层序列可以建立精确的纹层年代学, 为其 他指标提供可靠的时间标尺,为开展晚第四纪高分辨率古环境研究提供了有利条件 ${ }^{[2-4,8]}$.

目前利用湖泊年纹层进行的古环境研究集中在欧洲 ${ }^{[8-14]}$ 、北美洲 ${ }^{[15-16]}$ 和日本岛 ${ }^{[17-19]}$ 等地区. Ojala 等 ${ }^{[4]}$ 基于 2011 年 6 月以前全球正式发表的纹层沉积物年代学研究建立了纹层年代数据库( Varve Data Base,

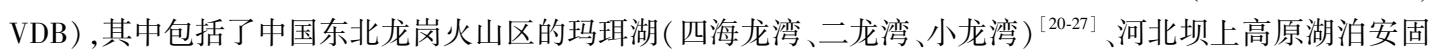
里淖 ${ }^{[28]}$ 和柴达木盆地的苏干湖 ${ }^{[29]}$ ( 图 1). 我国湖泊沉积物年纹层研究起步较晚, 但是发展很快, 青藏高原地 区新路海 ${ }^{[30]}$ 和库赛湖 ${ }^{[31]}$ 等湖泊纹层研究在国际顶级期刊陆续发表. 然而, 我国目前的湖泊沉积物年纹层研 究主要是利用年纹层厚度和组分变化所提供的气候信息重建过去环境历史 ${ }^{[20-22,30-32]}$, 对纹层年代学的方法、 误差估计等方面的研究稍显不足.

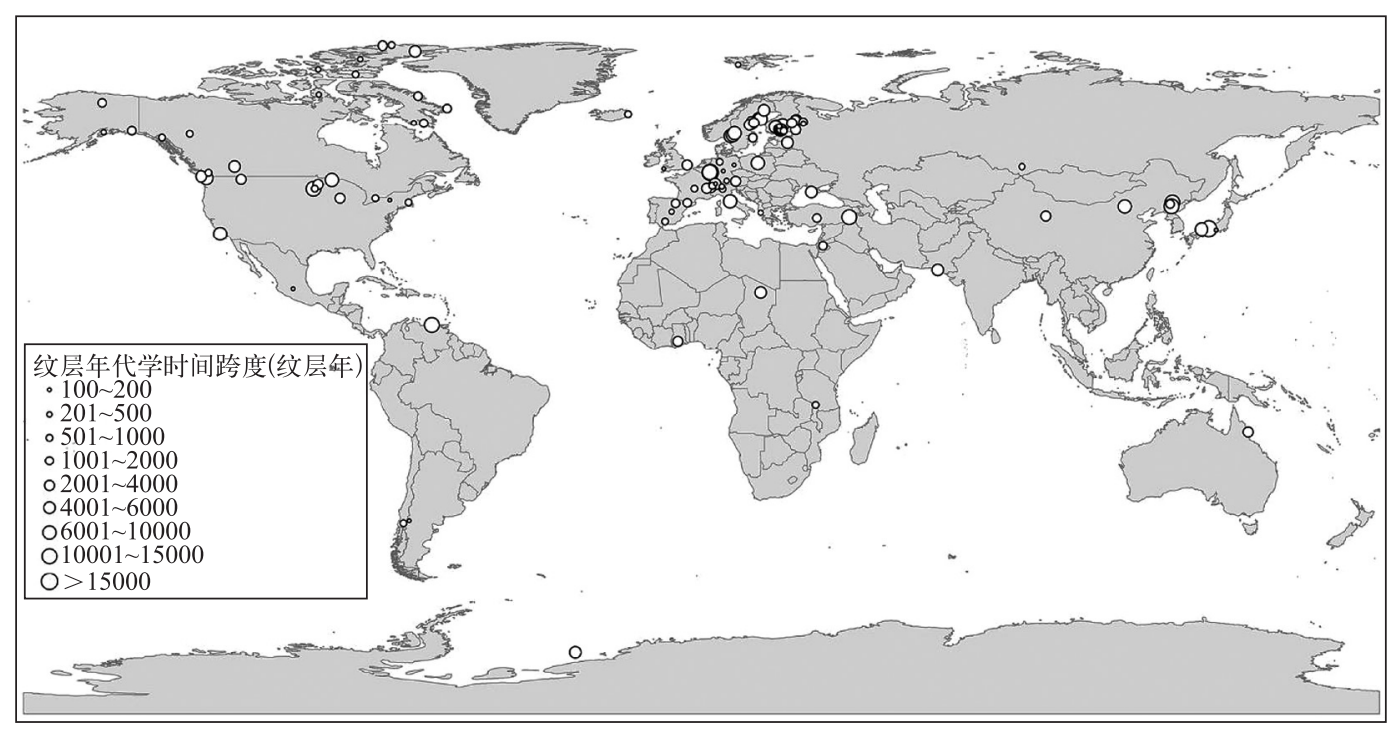

图 1 世界范围沉积物纹层年代学时间范围 (引自 Ojala 等 ${ }^{[4]}$ )

Fig.1 Temporal extension of varve chronologies worldwide( cited from Ojala et $a l^{[4]}$ )

对于古环境研究来说, 年纹层沉积物最重要的贡献是能够建立可靠的纹层年代学时间标尺 ${ }^{[4,8,33]}$. 例如 在芬兰 Lehmilampi 湖, 过去 $2000 \mathrm{a}$ 间纹层年代计数误差仅为 $-44 \mathrm{a}$ 和 $+46 \mathrm{a}^{[14]}$; 在我国东北二龙湾玛珥湖, 过去 $11198 \mathrm{a}$ 纹层年代误差仅为 $\pm 316 \mathrm{a}^{[21]}$. 湖泊沉积物纹层年代学已成为晚第四纪古环境研究中非常重要 的年代学手段, 为高分辨率古环境 (事件) 研究提供了坚实的基础 ${ }^{[4,8,33]}$. 近年来, 随着我国青藏高原地区的 新路海 ${ }^{[30]}$ 、库赛湖 ${ }^{[31]}$ 、巴松错和江错 (未发表数据) 以及缅甸 Twintaung 玛珥湖 ${ }^{[35]}$ 等具有纹层发育的湖泊被 发现, 湖泊沉积物纹层年代学研究急需进一步深人. 基于此, 本文在 VDB 的基础上, 总结了中国湖泊沉积物 纹层年代学研究进展, 以期对中国湖泊年纹层的进一步发展提供借鉴.

\section{1 我国湖泊年纹层沉积物概况}

我国目前发表的湖泊沉积物年纹层集中在东北龙岗火山区以及青藏高原地区.从年纹层特征来看,均与 季节性的物源输人以及湖泊自身生产力变化有关.已报导的年纹层类型包括碎屑沉积年纹层、生物沉积年纹 层和化学沉积年纹层, 基本包含了 Ojala 等 ${ }^{[4]}$ 和 Zolitschka 等 ${ }^{[8]}$ 建议的纹层类型. 从空间上看,东北龙岗火山 区的玛珥湖主要发育有生物一碎屑年纹层, 青藏高原地区的新路海和库赛湖主要发育有碎屑年纹层, 而西部 干旱区的苏干湖主要发育有化学沉积年纹层(表 1 ). 
表 1 中国的年纹层沉积物分布

Tab.1 Varved lake sediments in China

\begin{tabular}{|c|c|c|c|c|c|c|c|}
\hline 湖泊 & 地理位置 & $\begin{array}{l}\text { 平均 } \\
\text { 海拔 } / \mathrm{m}\end{array}$ & $\begin{array}{c}\text { 湖水面积/ } \\
\mathrm{km}^{2}\end{array}$ & $\begin{array}{c}\text { 流域面积 } \\
\mathrm{km}^{2}\end{array}$ & $\begin{array}{l}\text { 最大 } \\
\text { 水深 } / \mathrm{m}\end{array}$ & 年纹层类型 & 文献 \\
\hline 四海龙湾 & $42^{\circ} 25^{\prime} \mathrm{N}, 126^{\circ} 32^{\prime} \mathrm{E}$ & 797 & 0.5 & 0.70 & 50 & 硅藻年纹层、碎屑年纹层 & {$[20]$} \\
\hline 二龙湾 & $42^{\circ} 18^{\prime} \mathrm{N}, 126^{\circ} 21^{\prime} \mathrm{E}$ & 724 & 0.3 & 0.40 & 36 & $\begin{array}{l}\text { 硅藻年纹层、甲藻年纹层、碎屑年 } \\
\text { 纹层 }\end{array}$ & [21] \\
\hline 小龙湾 & $42^{\circ} 18^{\prime} \mathrm{N}, 126^{\circ} 19^{\prime} \mathrm{E}$ & 655 & 0.1 & 0.15 & 15 & $\begin{array}{l}\text { 甲藻年纹层、金藻年纹层、碎屑年 } \\
\text { 纹层 }\end{array}$ & {$[22]$} \\
\hline 苏干湖 & $38^{\circ} 51^{\prime} \mathrm{N}, 93^{\circ} 54^{\prime} \mathrm{E}$ & 2795 & 103.7 & 19854.00 & 6 & $\begin{array}{l}\text { 单水方解石 }- \text { 有机质纹层、白云 } \\
\text { 石-有机质纹层、碎首 }- \text { 硅藻 (碎 } \\
\text { 屑) 纹层、文石-有机质纹层 }\end{array}$ & {$[29]$} \\
\hline 新路海 & $39^{\circ} 49^{\prime} \mathrm{N}, 99^{\circ} 06^{\prime} \mathrm{E}$ & 4020 & 3.3 & 75.00 & 65 & 黏土层( 冬季沉降)-粉砂年纹层 & {$[30]$} \\
\hline 库赛湖 & $\begin{array}{l}35^{\circ} 37^{\prime} \sim 35^{\circ} 50^{\prime} \mathrm{N} \\
92^{\circ} 38^{\prime} \sim 93^{\circ} 15^{\prime} \mathrm{E}\end{array}$ & 4475 & 254.4 & 3700.00 & 60 & $\begin{array}{l}\text { 粗颗粒深色层 ( 冬季) - 细颗粒浅 } \\
\text { 色层 (夏季) }\end{array}$ & {$[31]$} \\
\hline
\end{tabular}

四海龙湾、二龙湾、小龙湾玛珥湖均位于东北吉林省龙岗火山区内.玛珥湖作为一种特殊类型的火山口 湖, 通常具有封闭无外泄且水深相对较深的特征, 有利于季节性年纹层的保存 ${ }^{[25,33]} .1929$ 年日本专家首先对 龙岗火山区进行了地质考察研究 ${ }^{[36]}$, 随后学者对龙岗火山区的 8 个玛珥湖进行了湖泊形态测量, 根据湖泊 表面积及相对深度的关系作图, 显示同处于该区的小龙湾、二龙湾及四海龙湾玛珥湖可能发育有良好的年 纹层, 后经过重力钻获取岩芯观察, 发现它们的确保存有年纹层 ${ }^{[20]}$. 年纹层类型主要为硅藻年纹层、甲藻年 纹层、金藻年纹层和碎屑年纹层 ${ }^{[20-22]}$.

苏干湖位于柴达木盆地北部, 是一个类似肾形的封闭湖泊. 钻孔岩芯研究发现, 苏干湖水深大于 $3 \mathrm{~m}$ 的 沉积物均具有裸眼可分辨的由深色层和浅色层组成的纹层层理 ${ }^{[29]}$. 通过显微观察、扫描电镜 (SEM) 分析、X 衍射分析及沉积物捕获实验, 对苏干湖纹层的结构、季节演替及形成过程进行了研究, 证实该湖水深 $3 \mathrm{~m}$ 以 下的层状沉积物为年纹层 ${ }^{[29]}$.

新路海位于青藏高原的东部山地, 是我国最大的冰川终碛堰塞湖 ${ }^{[37]}$. 新路海中部钻孔沉积物具有亮色 层和暗色层组成的层偶. 新路海为冰川补给湖泊, 夏季冰川融水增加将较多的流域碎屑物质输人湖中, 而冬 季处于冰封状态, 湖水中悬浮的黏土沉降到湖底, 形成以粉砂为主的亮色层和以黏土为主的暗色层组成的 年纹层 ${ }^{[30]}$. 沉积物钻孔中的 ${ }^{137} \mathrm{Cs}$ 与 ${ }^{210} \mathrm{~Pb}$ 测年结果与纹层计数结果基本一致, 支持了新路海纹层为年纹层的 观点 ${ }^{[30]}$.

库赛湖位于青藏高原北部可可西里国家级自然保护区境内, 为高原内陆咸水湖 ${ }^{[37]}$. 根据库赛湖钻孔沉 积物观察发现, 库赛湖沉积物发育有明显的深色层和浅色层组成的层偶. 其中, 深色层来源于冬季风力搬运 的粗颗粒物质, 而浅色层是在夏季湖泊分选作用、生物作用和化学作用下沉积的以细碎屑矿物、生物残体和 自生碳酸盐沉积为主的细颗粒层 ${ }^{[31]}$. 库赛湖冬季封冻、风力强劲, 风的机械搬运作用使大量的陆源物质在冰 面堆积, 等到春季湖泊开封, 冰面上粗颗粒物质沉积到湖底形成库赛湖年纹层的深色层 (粗颗粒层); 夏季温 度升高, 冰雪融化, 降水增加, 河流搬运的陆源粗颗粒物质由于重力作用先在湖泊边缘沉积, 而黏土矿物等 细颗粒物质则在湖泊中心沉积, 同时夏季湖水温度升高, 蒸发作用加强, 生物活动增强, 湖泊自身的生物、化 学作用加强,从而形成以细碎屑矿物、生物残体、自生碳酸盐沉积为主的浅色层 (细颗粒层 $)^{[31]}$.

\section{2 纹层年代学研究}

湖泊年纹层沉积物可以提供独立的、连续的时间标尺.沉积物年代标尺的建立, 首先要进行年纹层鉴定 以及沉积过程解释, 然后进行年纹层计数并正确估计可能的误差, 最后对纹层年代学进行验证 ${ }^{[8]}$. 其中年纹 层的鉴定是纹层年代学的前提, 年纹层计数是纹层年代学的关键. 如果沉积序列是从现代开始的, 即水-沉 积物界面作为精确的时间控制点, 对应的纹层年代序列就可以作为绝对年代 ${ }^{[4,8]}$. 


\section{1 年纹层年际特征的鉴定}

年纹层的年际特征鉴定可以利用沉积物捕获器进行定期采样,通过显微镜观察、SEM 分析和矿物衍射 分析等手段,确定不同时间的沉积物生物特征和矿物特征等.例如,储国强等 ${ }^{[27]}$ 和 Zhou 等 ${ }^{[29]}$ 分别对四海龙 湾和苏干湖进行了捕获器采样. 但在采样成本很高或者捕获器容易丢失的部分地区, 沉积物捕获器并不适 用, 如新路海 ${ }^{[30]}$ 和库赛湖 ${ }^{[31]}$. 取而代之的是对无扰动的沉积物钻孔岩芯进行详细的矿物、生物地层学研究 分析,包括显微镜和 SEM 观察、岩芯 X 衍射和同步辐射扫描、X 射线苂光微区分析等, 以明确不同结构的组 分特征和环境指示意义, 进而明确年纹层的结构、组分特征和类型 ${ }^{[8,30-31]}$. 除此之外, 固定时间间隔的沉积钻 孔采样对比以及冷冻采样技术的运用也是证实年纹层结构组分的有效手段 ${ }^{[8]}$.

玛珥湖的深水环境和高的沉积速率有利于有机质和生物的保存 ${ }^{[33]}$. 通过大薄片分析研究年纹层的显微 结构, 四海龙湾、二龙湾和小龙湾玛珥湖主要年纹层类型为生物年纹层及碎屑年纹层 (图 2), 但根据藻类的 种类及丰度又可以将生物年纹层分为不同的亚层. 四海龙湾玛珥湖中硅藻生物年纹层由暗色硅藻微层和浅 色碎屑物、有机质层组成 ${ }^{[24]}$; 二龙湾玛珥湖中的甲藻生物年纹层 (甲藻含量 $>95 \%$ ) 是由厚的甲藻微层及碎 屑夹杂生物残体的微层组成, 甲藻与硅藻混合生物年纹层是由亮色的碎屑微层、介于亮暗色之间的混合微 层以及较厚的暗色甲藻硅藻微层组成 ${ }^{[21]}$; 小龙湾玛珥湖中的甲藻生物年纹层是由深棕色的甲藻与金藻孢囊 混合层及碎屑层组成 ${ }^{[26]}$. 根据对龙岗火山区玛珥湖水体中沉积物逐月捕获实验研究表明,9 和 11 月分别是 硅藻和甲藻的繁盛期 ${ }^{[27]}$, 表明生物年纹层中的藻类具有明确的季节指示意义, 从而说明该区生物年纹层具 有 “年”特征. 另外, 碎屑年纹层主要表现为粗颗粒陆源物质和细粒沉积物交替组成,这代表一年沉积的粒径 渐变特征,粗颗粒物质代表春夏季节,细颗粒沉积物代表秋冬季节.

基于沉积物收集装置的现代过程研究发现, 苏干湖夏季以浅色的单水方解石为主, 冬半年以深色有机 质为主. 岩芯中共有 4 种类型的纹层沉积 (图 2) : 单水方解石-有机质纹层、白云石-有机质纹层、碎屑-硅藻 纹层和文石-有机质纹层,且都具有季节特征, 属可靠的年纹层 ${ }^{[29]}$.

新路海沉积物纹层大薄片镜下鉴定结果显示, 浅色层以粉砂组分为主,形成于春夏季节冰川融水和夏 季大气降水增加条件下的快速沉积作用; 而暗色层主要由黏土组成, 形成于秋-冬季湖水中悬浮的黏土等细 颗粒组分的沉降作用 ${ }^{[30]}$. 在明确的亮色层内部可见一些夹层, 可能对应于年内的冰雪融水或者降水的突然 增加,但是浅色粉砂层和暗色黏土层仍然具有明确的季节特征, 属于可靠的年纹层 ${ }^{[30]}$.

陈铎等 ${ }^{[38]}$ 通过对沉积物纹层大薄片显微镜观察, 以及 SEM 分析、X 衍射和同步辐射、 $X$ 射线苂光等微 区分析, 进一步证实了库赛湖年纹层的形态、沉积和成分特征. 库赛湖年纹层由深浅相间的微层组成, 深色层 主要由灰褐色-黑褐色的粗颗粒物质组成, 磨圆中等、分选性差, 矿物以石英、长石、白云母、黏土矿物等为 主, 其中石英含量占 $73 \%$ 左右, 且具有明显的风力搬运特征; 浅色层呈灰白色, 矿物颗粒较细, 除石英、长石、 白云母、黏土外, 还有自生的文石, 同时浅色层中含有大量的枝角类碎片和半月形介形类生物壳体. 因此, 库 赛湖的年纹层是由冬季冰面风成物质形成的粗颗粒深色层 (冰融化后, 风成物质沉降至湖底堆积) 和夏季沉 积的细颗粒浅色层两者交替而形成的.

\section{2 年纹层计数}

年纹层计数是纹层年代学建立的关键 ${ }^{[15,34]}$. 年纹层计数的精确度取决于正确区分年纹层的类型、组分 和结构等 ${ }^{[8]}$. 在样品未扰动的前提下, 选择一种合适的计数方法是建立纹层年代学最重要的一个方面. 目前 在 VDB 记录的纹层年代序列中主要运用 2 种方法进行年纹层计数 ${ }^{[4]}$ : 第 1 种方法是用数码相机对新鲜沉积 物照相, 得到高质量的图片, 然后利用 Photoshop 等软件程序进行年纹层人工计数; 第 2 种方法是利用冷冻 干燥法-树脂固定等来制作沉积物岩相学大薄片, 显微镜下分析年纹层特征并进行年纹层人工计数工作.

照片计数方法对于具有明显的标志层或者沉积速率较高的年纹层来说, 是简单可行的方法.Zhou 等 ${ }^{[29]}$ 用该种方法统计了苏干湖沉积物纹层数并测量了层偶厚度. 但是, 即使是发育最好的年纹层也有不规则的趋 势或者微小的扰动, 这就导致运用图像分析软件对年纹层计数必将会产生一个不可避免的误差. 因此, 第 1 种方法适用于厚度在 $0.5 \mathrm{~mm}$ 以上, 而且标志层非常清晰的年纹层计数 ${ }^{[4]}$.

大薄片方法对于沉积速率非常低、年纹层厚度非常薄的湖泊沉积物来说, 应该是最适合的方法. 目前越 来越多的湖泊沉积物纹层年代学研究运用第 2 种方法建立纹层年代学时间标尺 ${ }^{[4]}$. 刘强等 ${ }^{[39]}$ 对岩相学大薄 

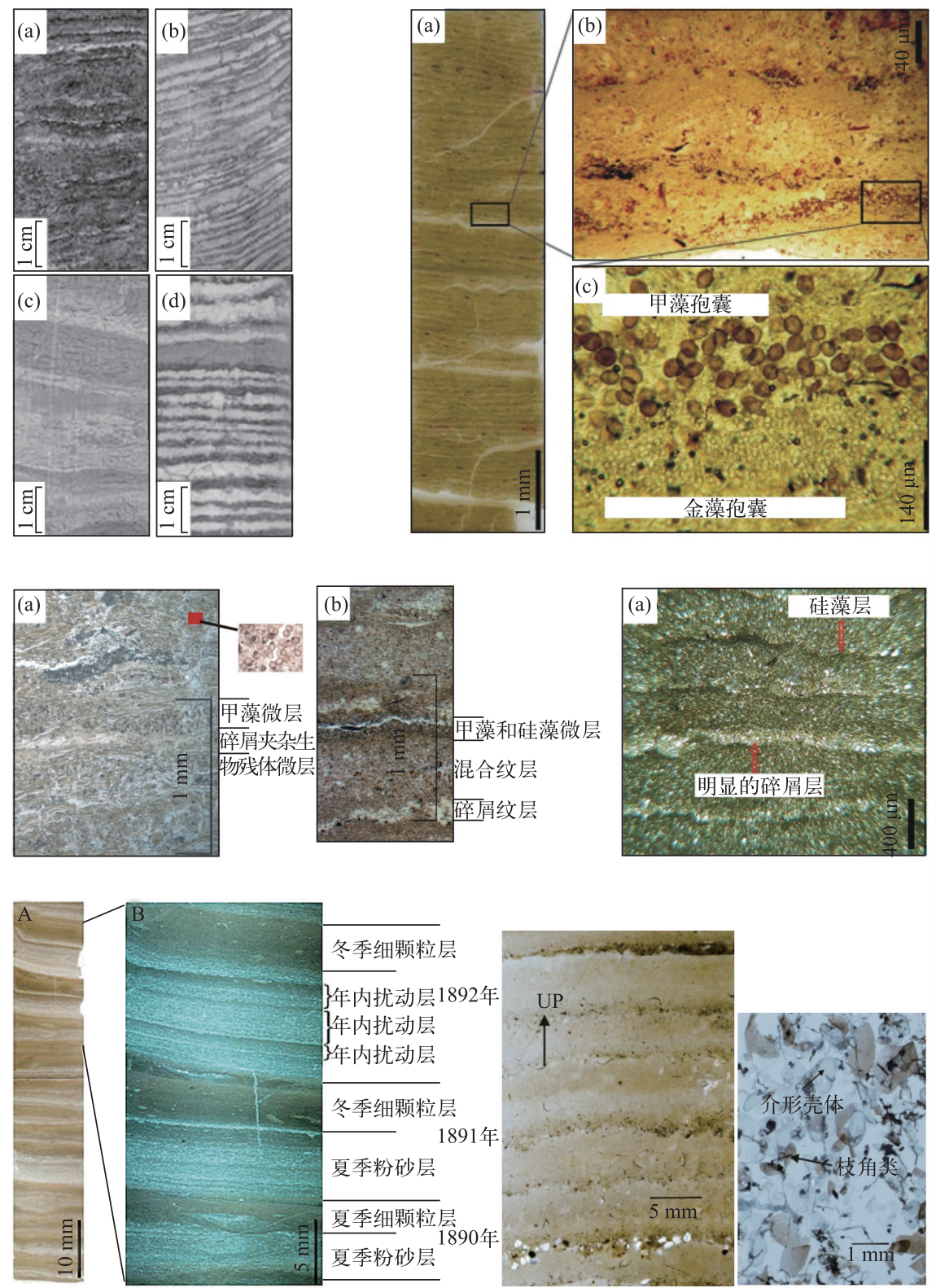

图 2 中国正式发表的年纹层类型 (左上图为苏干湖沉积物 ${ }^{[29]}$ : ( a ) 单水方解石-有机质纹层, (b) 白云石一有机质纹层, (c) 碎屑-有机质纹层, (d) 文石-有机质纹层; 右上图为小龙湾玛珥湖 沉积物 ${ }^{[26]}$ : ( a ) 大薄片扫描图片, (b) 甲藻生物年纹层, (c) 甲藻和金藻混合部分; 中间左图为二龙湾玛珥湖沉积物 ${ }^{[21]}$ : ( a ) 甲藻生物年纹层, (b) 甲藻和硅藻混合生物年纹层; 中间右图为四海龙湾玛珥湖沉积物 ${ }^{[24]}$ : ( a ) 硅藻生物-碎屑年纹层; 左下图为新路海沉积物:

冬季黏土-夏季粉砂年纹层 ${ }^{[30]}$; 右下图为显微镜下库赛湖年纹层特征及生物残体 (浅黄褐色薄片状为枝角类, 亮色的半月形为介形类壳体) ${ }^{[31]}$ )

Fig.2 Varve types in lake sediments reported in China

片制作技术进行过介绍. 目前, 国内主要利用冷冻干燥-树脂固定法来制作沉积物岩相学大薄片, 此方法由 Merkt ${ }^{[40]}$ 在 1971 年提出, 详细方法参文献 [ 41].东北龙岗火山区的 3 个玛珥湖利用第 2 种方法, 得到了可靠 
的纹层年代学数据 ${ }^{[20-22,24,26,41]}$. 青藏高原的新路海以及库赛湖也采用了第 2 种方法 ${ }^{[30-31]}$. Chu 等 ${ }^{[31]}$ 对新路海 沉积物纹层大薄片进行高分辨率扫描, 在可数字化的软件下进行纹层计数并测量纹层厚度,得到了可靠的 纹层年代序列; 而 Liu 等 ${ }^{[31]}$ 对库赛湖沉积物纹层大薄片在体式显微镜下进行纹层计数并测量纹层厚度, 得 到可靠的纹层年代学序列.

除了以上常用的 2 种方法外, 扫描电镜技术、数字化图像技术和同步辐射分析技术也被应用到纹层年 代学研究中来 ${ }^{[4,8,45]}$,多种方法联合使用可以大大提高纹层年代学结果的精确度 ${ }^{[8]}$. 游海涛等和 Chu 等使用 $\mathrm{X}$ 射线同步辐射技术进行相关研究 ${ }^{[46-47]}$, 虽然没有用于年纹层时间序列的建立, 但是同步辐射技术在国内 沉积物纹层研究中的应用前景仍然值得期待.

年纹层计数多采用人工计数的方法, 这也是国内纹层年代学研究普遍采用的方法 ${ }^{[20-32]}$. 目前也有国外 学者通过自动化 ${ }^{[42]}$ 和半自动化 ${ }^{[43]}$ 软件程序对新鲜沉积物或者岩芯大薄片扫描图像进行纹层计数, 得到较 为可靠的纹层年代学数据 ${ }^{[4,8]}$. 相较于人工计数, 自动化计数手段提供了快速、客观的计数方式, 可以大大减 少年纹层计数所需要的时间 ${ }^{[8]}$. 但是从年代学的观点来看,这种技术的局限性在于它仅适用于有明显“年” 边界的年纹层计数 ${ }^{[44]}$. 湖泊沉积物受到地质、水文、气候和生物等多种因素的影响, 其发育的纹层有时候是 不规则的, 即使在同一钻孔中, 不同深度层位的沉积纹层特征也是不尽相同的 ${ }^{[29-30]}$. 所以对于年纹层结构特 征十分明显、发育比较规则并且保存较好的年纹层沉积物可以采用(半) 自动计数,但是人工计数验证仍然 是必不可少的环节.

\section{3 纹层年代学的误差来源及控制}

De Geer ${ }^{[48]}$ 在 1939 年首次提出由于沉积物本身以及观察者带来的纹层计年误差,随后学者们对纹层年 代学的精度也进行了大量的主观描述 ${ }^{[5]}$.Saarnisto ${ }^{[6]}$ 在 1979 年强调沉积物纹层年代序列需建立在详细的年 纹层计数基础上, 之后纹层年代序列的误差估计才开始逐渐定量化 ${ }^{[4]}$. 沉积物纹层年代学的误差主要由沉积 物钻探取样或者分样时的沉积物扰动, 由于湖底扰动、流域/湖岸侵蚀、滑塌以及地震等引起的再悬浮等导 致的年纹层不清晰或者缺失, 或者由于观察计数者主观不确定性而致 ${ }^{[4,47]}$. 在沉积物年纹层计数过程中常见 的错误主要有 3 种类型 ${ }^{[15]}:$ : (1) 年纹层不明显而遭到忽视, (2) 将扰动层鉴定为年纹层, (3) 年纹层在某一深 度缺失.

纹层年代学误差为沉积物钻孔某一深度计数得到的可能最大年龄和最小年龄之差, 记为土纹层年, 或者

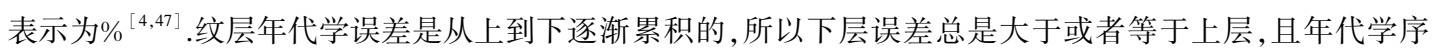
列最大误差多出现在钻孔底部 ${ }^{[47]}$. 单个钻孔的纹层计年误差可以采用加减层法、纹层质量分级法以及重复 测量法进行估算 ${ }^{[31,49]}$. 从目前VDB 所收集的全球纹层年代序列来看, 各个湖泊纹层年代学的误差估计并没 有标准的方法 ${ }^{[4]}$, 但使用最多的方法是交叉检验, 即单人多次或者多人多次对同一个湖泊多个岩芯钻孔进 行年纹层计数 ${ }^{[15]}$. 交叉检验能够大大减少由于统计人员的主观不确定性所带来的误差, 以及由于湖底地形 差异、水动力环境差异、湖岸滑塌和湖底生物扰动等因素引起的纹层扰动、缺失等带来的误差. 在沉积物纹层 年代学研究过程中, 标志层是进行交叉验证和多钻孔对比的关键 ${ }^{[15,41]}$. 纹层计数之前, 首先需要用低倍度显 微镜或者肉眼对非常明显的标志层进行标记 ${ }^{[41]}$.标志层可以是发育十分完好、特征十分明显或者肉眼可辨 别的层位 ${ }^{[15]}$. 依据标志层来进行沉积物年纹层分段计数对比以及多钻孔对比, 最后统计得到的年纹层数目 进行复验以确定误差年限 ${ }^{[15]}$.

在我国已有的纹层沉积物年代学研究中, 除苏干湖沉积物纹层年代学误差未交代清楚之外 ${ }^{[29]}$, 东北龙 岗火山区的玛珥湖以及青藏高原的新路海和库赛湖都进行了交叉检验, 其中四海龙湾以及新路海短岩芯进 行了多钻孔对比. Mingram 等 ${ }^{[20]}$ 在四海龙湾纹层计数过程中结合了冷冻岩芯扫描图像、纹层沉积物大薄片以 及显微镜图像进行了年纹层计数; 计数过程中结合火山灰层和碎屑层等显著的标志层来进行误差控制. You 等 ${ }^{[21]}$ 对二龙湾沉积物纹层大薄片进行了多人多次计数, 全新世起始阶段的年代学误差仅为 $2 \%( \pm 316 \mathrm{a})$. Chu 等 ${ }^{[24]}$ 对四海龙湾和小龙湾岩芯大薄片进行了交叉检验, 结合标志层进行多钻孔对比.Chu 等 ${ }^{\left[{ }^{[0]}\right.}$ 对新路 海沉积岩芯进行了多岩芯钻孔对比,基本消除了计年误差.

由于长岩芯纹层序列的制备和计数工作耗时很长, 例如四海龙湾和二龙湾 ${ }^{[21,41]}$, 或者在我国西部一些 地区沉积物长岩芯取样工作有诸多不便, 例如库赛湖采样成本高且作业条件艰苦 ${ }^{[31]}$, 多钻孔对比的实现有 
很大难度. 因此, 在长序列钻孔纹层年代学研究中可以结合标志层进行多人多次独立计数: 对一些标志层区 间内多人计数结果存在很大分歧的部分重新校验, 并正确评估存在的误差; 对年纹层缺失的少数情况可以 使用临近层位的平均沉积速率进行推算 ${ }^{[31]}$, 该段计年误差记为土纹层年 (层数). 除此之外, 也可以采用年纹 层质量分级法 ${ }^{[49]}$, 根据沉积物年纹层的质量 (可辨认程度) 分为 $0 \sim 3$ 级, 对应的误差分别为 $15 \%$ ( 0 级)、 $5 \%$ ( 1 级) 和 $1 \%$ (2 3 级), 其整体误差采用加权平均法获得 ${ }^{[31]}$.

在以后的纹层年代学误差估计中, 尤其需要注意由观察者漏计年纹层引起的误差以及由错误鉴定“年” 纹层特征引起的误差. 这两类误差很可能都源于沉积物的扰动、结构的破坏以及操作人员经验的缺乏 ${ }^{[4]}$. 所 以在这里需要强调的是, 沉积物必须尽可能地无扰动、无缺失, 年纹层计数必须要进行交叉验证, 尽量用多 个平行钻孔岩芯来建立纹层年代学, 并且操作人员一定要具备丰厚的经验. 如果纹层年代学是基于单个长沉 积钻孔建立的, 其年代学误差更需要多种方法的结合验证, 包括纹层质量分级法和独立重复计数法 ${ }^{\left[{ }^{[1]}\right.}$, 以期 提供较为精确的误差控制.

\section{4 纹层年代学的验证}

在高时间分辨率下分析沉积物时, 年代学的准确性是至关重要的 ${ }^{[8,33]}$. 纹层年代学是建立在层偶确切在 一年之内沉积的基础之上的, 由于建立纹层年代学过程中不可避免地存在着内在的系统误差(例如纹层发 育不规则、纹层保存较差等) 和在分析计数过程中未检测到的偶然误差, 所以利用其他独立的定年方法来验 证纹层年代学的可信度就显得非常重要 ${ }^{[2-3,8,16,50-51]}$. 即使是年纹层特征和界限非常明确, 也仍然需要进行独 立的年代学方法验证 ${ }^{[5,7,49]}$, 以提高纹层年代学的准确性 ${ }^{[4,33]}$. 常用的验证法方法包括: 常规 ${ }^{14} \mathrm{C}$ 定年、 $\mathrm{AM} \mathrm{S}^{14} \mathrm{C}$ 定年、 ${ }^{210} \mathrm{~Pb}$ 定年、 ${ }^{137} \mathrm{Cs}$ 定年、古地磁曲线 (PSV 或者 RPI)、火山灰定年或者其他事件定年手段 ${ }^{[4,33]}$. 其中, ${ }^{14} \mathrm{C}$ 定年不仅可以用来验证纹层年代学的正确性, 同时, 纹层年代学还可用来研究 ${ }^{14} \mathrm{C}$ 定年中存在的相关问题、 延伸 ${ }^{14} \mathrm{C}$ 校正曲线的范围 ${ }^{[31,33,51-52]}$. 高分辨率纹层年代学揭示了苏干湖和库赛湖的碳库效应并不是固定的, 均存在很大的变化范围, 其中苏干湖在过去 $2732 \mathrm{a}$ 的沉积物存在的碳库效应变化范围为 $2590 \sim 4340 \mathrm{a}^{[53]}$, 而库赛湖在过去 $1600 \mathrm{a}$ 的沉积物存在的碳库效应约为 $3180 \pm 457$ a. 库赛湖精确的纹层年代学 ${ }^{\left[{ }^{[1]}\right.}$ 与古地磁 的对比有望提供区域晚全新世的古地磁曲线特征, 为校正碳库效应提供参考.

我国纹层年代学大多运用常规 ${ }^{14} \mathrm{C} 、 \mathrm{AMS}{ }^{14} \mathrm{C} 、{ }^{210} \mathrm{~Pb} 、{ }^{137} \mathrm{Cs}$ 定年以及火山灰事件定年等方法来进行验证, 且都有较好的一致性 ${ }^{[22,24,26,29-31]}$. 需要说明的是, 河北坝上高原安固里淖报导的年纹层并不可信, 其纹层年代 学也缺少必要的验证. 据 Zhai 等 ${ }^{[28]}$ 的描述, 安固里淖 $1.6 \mathrm{~m}$ 沉积物 (实际缩水至 $74 \mathrm{~cm}$, 且研究仅使用了 $0 \sim$ $61 \mathrm{~cm}$ ) 在 SEM 拍照之后进行的人工计数达到了 8432 纹层年, 且与常规 ${ }^{14} \mathrm{C}$ 年龄基本一致. 但是, 刘兴起和李 凯在安固里淖沉积钻孔中 $\left(2010\right.$ 年采集, 进深 $38 \mathrm{~m}$ ) 挑出的碳屑 (深度为 $2.4 \mathrm{~m}$ ) $\mathrm{AMS}^{14} \mathrm{C}$ 测年结果为 $3995-$ $3896 \mathrm{cal} \mathrm{a} \mathrm{BP}$ ( 未发表数据 ${ }^{\circledR}$ ). 我们认为 Zhai 等 ${ }^{[28]}$ 所用的常规 ${ }^{14} \mathrm{C}$ 测年结果受 “碳库效应” 影响而比实际年 龄偏老. 因此, 对纹层年代学科学的验证需要使用多种定年方法来进行.

\section{3 认识及展望}

与树轮、珊瑚、冰芯一样, 年纹层沉积物由于具有季节和年分辨率的沉积旋回, 因而可以建立高精度的 纹层年代学时间标尺. 如果沉积物剖面从沉积物一水界面处向底部一直发育有良好的年纹层, 可以认为建立 的纹层年代学是绝对独立且连续的; 反之, 则可作为 “浮动的” 时间标尺, 此时必须借助于精准的年龄点控 制 ${ }^{[4,8,49]}$. 沉积物纹层年代学的发展, 为开展高分辨率古环境气候研究提供了很好的基础 ${ }^{[33,49]}$. 纹层年代学时 间标尺不仅为环境一气候指标记录提供了天然年历, 而且补充了树木年轮年代长度的不足, 为校正 ${ }^{14} \mathrm{C}$ 年龄 提供了又一种重要的途径 ${ }^{[52]}$. 除了在年代学, 年纹层厚度和组分特征可用来记录环境变化, 相较于树轮, 年 纹层可以提供的信息更为丰富,能发挥更为重要的贡献.

我国湖泊分布范围广,类型多样,基于湖泊沉积物进行的古环境研究已经广泛开展 ${ }^{[55]}$.但是,在我国广 阔的西部地区尤其是青藏高原地区, 多数湖泊存在“碳库效应” ${ }^{[54]}$, 限制了晚第四纪-全新世的古环境研究. 近年来,越来越多的纹层湖泊在我国青藏高原地区被发现, 无疑预示着中国湖泊纹层沉积物研究在探索晚

(1) 测年材料为陆生植物碳屑, 2015 年在新西兰 Rafter 实验室进行了 $\mathrm{AMS}^{14} \mathrm{C}$ 测试, 实验室样品编号为 NZA-57912.) 
第四纪环境演变方面将起到更加重要的作用.然而与国外相比较, 中国纹层年代学的发展虽然建立了几条高 精度的时间序列, 但湖泊沉积物纹层研究工作还处于起步阶段,在纹层年代学方法上仍然需要提高. 以下几 个方面也是我国未来湖泊纹层年代学研究必须考虑的: (1) 年纹层的组分以及形成机理; (2) 连续且无扰动 的沉积物取样技术; (3) 采用交叉检验; (4) 纹层年代学的验证.

\section{4 参考文献}

[ 1 ] De Geer G. Geochronology of the last 12,000 years. Milestones in geosciences. In: Wolf-Christian D ed. Berlin Heidelberg: Springer, 2003: 100-110.

[ 2 ] Sirocko F, Dietrich S, Veres D et al. Multi-proxy dating of Holocene maar lakes and Pleistocene dry maar sediments in the Eifel, Germany. Quaternary Science Reviews, 2013, 62: 56-76.

[ 3 ] Tylmann W, Enters D, Kinder M et al. Multiple dating of varved sediments from Lake Łazduny, northern Poland: Toward an improved chronology for the last 150 years. Quaternary Geochronology, 2013, 20: 98-107.

[ 4 ] Ojala AE, Francus P, Zolitschka B et al. Characteristics of sedimentary varve chronologies-A review. Quaternary Science Reviews, 2012, 43: 45-60.

[ 5 ] O'Sullivan PE. Annually-laminated lake sediments and the study of Quaternary environmental changes-A review. Quaternary Science Reviews, 1983, (1) : 245-313.

[ 6 ] Saarnisto M. Annually laminated lake sediments. Handbook of Holocene Palaeoecology and Palaeohydrology, 1986,17 : 343-370.

[ 7 ] Zolitschka B. Dating based on freshwater and marine-laminated sediments. Global Change in the Holocene. In: Mackay A, Battarbee R, Birks J et al eds. New York: Hodder Education, 2003: 92-106.

[ 8 ] Zolitschka B, Francus P, Ojala A et al. Varves in lake sediments-A review. Quaternary Science Reviews, 2015,117 : $1-41$.

[ 9 ] Lehndorff E, Wolf M, Litt T et al. 15,000 years of black carbon deposition-A post-glacial fire record from maar lake sediments (Germany). Quaternary Science Reviews, 2015, 110: 15-22.

[10] Martin-Puertas C, Brauer A, Dulski P et al. Testing climate-proxy stationarity throughout the Holocene: An example from the varved sediments of Lake Meerfelder Maar (Germany). Quaternary Science Reviews, 2012,58: 56-65.

[11] Lücke A, Brauer A. Biogeochemical and micro-facial fingerprints of ecosystem response to rapid Late Glacial climatic changes in varved sediments of Meerfelder Maar (Germany). Palaeogeography, Palaeoclimatology, Palaeoecology, 2004, 211: 139-155.

[12] Romero-Viana L, Julia R, Camacho A et al. Climate signal in varve thickness: Lake La Cruz (Spain), a case study. Journal of Paleolimnology, 2008, 40: 703-714.

[13] Trachsel M, Grosjean M, Larocque-Tobler I et al. Quantitative summer temperature reconstruction derived from a combined biogenic Si and chironomid record from varved sediments of Lake Silvaplana (south-eastern Swiss Alps) back to AD 1177. Quaternary Science Reviews, 2010, 29: 2719-2730.

[14] Haltia-Hovi E, Saarinen T, Kukkonen M. A 2000-year record of solar forcing on varved lake sediment in eastern Finland. Quaternary Science Reviews, 2007, 26: 678-689.

[15] Lamoureux SF, Bradley RS. A late Holocene varved sediment record of environmental change from northern Ellesmere Island, Canada. Journal of Paleolimnology, 1996, 16: 239-255.

[16] Cook TL, Bradley RS, Stoner JS et al. Five thousand years of sediment transfer in a high arctic watershed recorded in annually laminated sediments from Lower Murray Lake, Ellesmere Island, Nunavut, Canada. Journal of Paleolimnology, 2009, 41: 77-94

[17] Kawakami I, Matsuo M, Kato M et al. Chronology and sedimentation process of varved lacustrine sediment in Lake Fukami, central Japan. Quaternary International,2004, 123: 27-34.

[18] Nakagawa T, Kitagawa H, Yasuda Y et al. Pollen/event stratigraphy of the varved sediment of Lake Suigetsu, central Japan from 15,701 to 10,217 SG vyr BP (Suigetsu varve years before present) : Description, interpretation, and correlation with other regions. Quaternary Science Reviews, 2005, 24: 1691-1701.

[19] Nakagawa T, Gotanda K, Haraguchi T et al. SG06, a fully continuous and varved sediment core from Lake Suigetsu, Ja- 
pan: Stratigraphy and potential for improving the radiocarbon calibration model and understanding of late Quaternary climate changes. Quaternary Science Reviews, 2012, 36: 164-176.

[20] Mingram J, Allen JR, Brüchmann C et al. Maar-and crater lakes of the Long Gang Volcanic Field ( NE China) - overview, laminated sediments, and vegetation history of the last 900 years. Quaternary International,2004, 123: 135-147.

[21] You H, Liu J, Liu Q et al. Study of the varve record from Erlongwan maar lake, NE China, over the last 13 ka BP. Chinese Science Bulletin, 2008, 53: 262-266.

[22] Chu G, Sun Q, Wang X et al. A 1600 year multiproxy record of paleoclimatic change from varved sediments in Lake Xiaolongwan, northeastern China. Journal of Geophysical Research: Atmospheres, 2009, 114 (D22).

[23] Schettler G, Liu Q, Mingram J et al. East-Asian monsoon variability between 15000 and 2000 cal. yr BP recorded in varved sediments of Lake Sihailongwan (northeastern China, Long Gang volcanic field). The Holocene, 2006, 16: 1043-1057.

[24] Chu G, Sun Q, Gu Z et al. Dust records from varved lacustrine sediments of two neighboring lakes in northeastern China over the last 1400 years. Quaternary International, 2009, 194: 108-118.

[25] Liu Jiaqi, Liu Dongsheng, Chu Guoqiang et al. Maar lake and varve chronology. Quaternary Sciences, 1996, 16: 353-358. [刘嘉麒, 刘东生, 储国强等. 玛珥湖与纹泥年代学. 第四纪研究, 1996, 16: 353-358. ]

[26] Chu G, Sun Q, Rioual P et al. Dinocyst microlaminations and freshwater "red tides" recorded in Lake Xiaolongwan, northeastern China. Journal of Paleolimnology, 2008, 39: 319-333.

[27] Chu Guoqiang, Gu Zhaoyan, Xu Bing et al. Varve chronology and radiometric dating $\left({ }^{137} \mathrm{Cs},{ }^{210} \mathrm{~Pb}\right)$ from the Sihailongwan Maar, Northeastern China. Quaternary Sciences, 2005, 25: 202-207. [储国强, 顾兆炎, 许冰等. 东北四海龙湾玛珥湖 沉积物纹层计年与 ${ }^{137} \mathrm{Cs},{ }^{210} \mathrm{~Pb}$ 测年. 第四纪研究, 2005, 25: 202-207.]

[28] Zhai Q, Guo Z, Li Y et al. Annually laminated lake sediments and environmental changes in Bashang Plateau, North China. Palaeogeography, Palaeoclimatology, Palaeoecology,2006, 241: 95-102.

[29] Zhou A, Chen F, Qiang M et al. The discovery of annually laminated sediments (varves) from shallow Sugan Lake in inland arid China and their paleoclimatic significance. Science in China Series D: Earth Sciences, 2007, 50: 1218-1224.

[30] Chu G, Sun Q, Yang K et al. Evidence for decreasing South Asian summer monsoon in the past 160 years from varved sediment in Lake Xinluhai, Tibetan Plateau. Journal of Geophysical Research: Atmospheres, 2011: 116 (D2).

[31] Liu X, Yu Z, Dong H et al. A less or more dusty future in the Northern Qinghai-Tibetan Plateau? Scientific Reports, 2014, 4: 6672. DOI: 10.1038/srep06672.

[32] Zhang K, Zhao Y, Yu Z et al. A 2700-year high resolution pollen record of climate change from varved Sugan Lake in the Qaidam Basin, northeastern Tibetan Plateau. Palaeogeography Palaeoclimatology Palaeoecology, 2010, 297: 290-298.

[33] Liu Jiaqi, Wu Jing, Chu Guoqiang et al. Progress of palaeoclimatic and palaeoenvironmental studies on maar lakes. Bulletin of Mineralogy, Petrology and Geochemistry, 2013, 32: 639-650. [刘嘉麒, 伍婧, 储国强等. 玛珥湖古气候环境研 究进展. 矿物岩石地球化学通报, 2013, 32: 639-650.]

[34] Ojala A. Varved lake sediments in southern and central Finland: Long varve chronologies as a basis for Holocene palaeoenvironmental reconstructions. Espoo: Geological Survey of Finland, 2001.

[35] Sun Qing, Shan Yabing, Su Youliang et al. Carbonate varves and minor element variations during the past 100 years in Maar Lake Twintaung, Myanmar. Chinese Science Bulletin, 2015, 11: 1038-1047. [孙青, 单雅冰, 苏有亮等. 缅甸 Twintaung 玛珥湖碳酸盐年纹层及 100 年来微区原位元素分析. 科学通报, 2015, 11: 1038-1047.]

[36] Tokyo Geological Survey, Geological Atlas of Eastern China. Tokyo, 1929.

[37] Wang Sumin, Dou Hongshen eds. Lakes in China. Beijing: Science Press, 1998. [王苏民, 窦鸿身. 中国湖泊志. 北京: 科学出版社, 1998.]

[38 C Chen Yu, Liu Xingqi, He Li et al. Methodology of studying on varve and its significance. Acta Geologica Sinica, 2016, 90 (5) : 1006-1015. [ 陈钰, 刘兴起, 何利等. 青藏高原北部可可西里库赛湖年纹层微区分析及形成机理. 地质学报, 2016, 90(5) : 1006-1015.]

[39] Liu Qiang, You Haitao, Liu Jiaqi. Methodology of studying on varve and its significance. Quaternary Sciences, 2004, 24: 683-694. [刘强，游海涛，刘嘉麒. 湖泊沉积物年纹层的研究方法及其意义. 第四纪研究, 2004, 24: 683-694.]

[40] Merkt J. Zuverlässige Auszählungen von Jahresschichten in Seesedimenten mit Hilfe von Gross-Dünnschliffen. Archiv für Hydrobiologie, 1971, 69: 145-154. 
[41] You Haitao, Liu Qiang, Liu Jiaqi et al. Research methodology prelimimary results for varved lacustrine sediments of the Sihailongwan Maar Lake. Earth and Environment, 2006, 34: 71-76. [游海涛, 刘强, 刘嘉麒等. 东北四海龙湾玛珥湖年 纹层的研究方法及初步成果. 地球与环境, 2006, 34: 71-76.]

[42] Weber M, Reichelt L, Kuhn G et al. BMPix and PEAK tools: New methods for automated laminae recognition and counting-Application to glacial varves from Antarctic marine sediment. Geochemistry, Geophysics, Geosystems, 2010, 11: 1-18. DOI: $10.1029 / 2009$ GC002611.

[43] Ojala AE, Tiljander M. Testing the fidelity of sediment chronology : Comparison of varve and paleomagnetic results from Holocene lake sediments from central Finland. Quaternary Science Reviews, 2003, 22: 1787-1803.

[44] Francus P ed. Image analysis, sediments and paleoenvironments. Dordrecht: Springer Science \& Business Media, 2006: 187-202.

[ 45] Kienel U, Bowen SW, Byrne R et al. First lacustrine varve chronologies from Mexico: Impact of droughts, ENSO and human activity since AD 1840 as recorded in maar sediments from Valle de Santiago. Journal of Paleolimnology, 2009, 42: 587-609.

[46] You Haitao, Sun Chunqing, Li Quanlin et al. Environment instruction significance and character of element geochemistry based on synchrotron radiation techniques from varved lake sediments of Erlongwan Maar Lake. Nuclear Techniques, 2015, 38(2). DOI: 10.11889/j.0253-3219.2015.hjs.38.020101. [游海涛, 孙春青, 李全林等. 二龙湾玛珥湖年纹层湖泊沉 积物元素的 X 射线苂光光谱分析. 核技术, 2015: 38(2).]

[47] Chu G, Sun Q, Li S et al. Minor element variations during the past 1300 years in the varved sediments of Lake Xiaolongwan, northeastern China. GFF, 2015, 135(3/4) : 265-272.

[48] De Geer G ed. Geochronologia suecica principles. Stockholm: Almqvist \& Wiksells, 1940.

[ 49] Brauer A, Casanova J. Chronology and depositional processes of the laminated sediment record from Lac d'Annecy, French Alps. Journal of Paleolimnology,2001, 25: 163-177.

[50] Snowball I, Muscheler R, Zillen L et al. Radiocarbon wiggle matching of Swedish lake varves reveals asynchronous climate changes around the $8.2 \mathrm{kyr}$ cold event. Boreas, 2010, 39: 720-733.

[51] Hajdas I, Bonani G, Zolitschka B. Radiocarbon dating of varve chronologies, Soppensee and Holzmaar lakes after ten years. Radiocarbon, 2000, 42: 349-353.

[52] Ramsey CB, Staff RA, Bryant CL et al. A complete terrestrial radiocarbon record for 11.2 to 52.8 kyr BP. Science, 2012, 338: $370-374$.

[53] Zhou A, Chen F, Wang Z et al. Temporal change of radiocarbon reservoir effect in Sugan lake, northwest China during the late Holocene. Radiocarbon, 2009, 51: 529-535.

[54] Hou J, D'Andrea WJ, Liu Z. The influence of ${ }^{14} \mathrm{C}$ reservoir age on interpretation of paleolimnological records from the Tibetan Plateau. Quaternary Science Reviews, 2012, 48: 67-79.

[55] Shen J. Spatiotemporal variations of Chinese lakes and their driving mechanisms since the Last Glacial Maximum: A review and synthesis of lacustrine sediment archives. Chinese Science Bulletin, 2012, 58: 17-31. DOI: 10.1007/s11434-0125510-7. 